\title{
A method for parameterising roughness and topographic sub-grid scale effects in hydraulic modelling from LiDAR data
}

\author{
A. Casas ${ }^{1,4}$, S. N. Lane ${ }^{2}$, D. Yu ${ }^{3}$, and G. Benito ${ }^{1}$ \\ ${ }^{1}$ Institute of Natural Resources, Consejo Superior de Investigaciones Científicas, 28006 Madrid, Spain \\ ${ }^{2}$ Institute Hazard, Risk and Resilience and Department of Geography, Durham University, Durham, DH1 3LE, UK \\ ${ }^{3}$ Department of Geography, Loughborough University, Loughborough, LE11 3TU, UK \\ ${ }^{4}$ Department of Land, Air, and Water Resources, University of California, Davis, CA 95616, USA
}

Received: 16 March 2010 - Published in Hydrol. Earth Syst. Sci. Discuss.: 12 April 2010

Revised: 28 July 2010 - Accepted: 3 August 2010 - Published: 17 August 2010

\begin{abstract}
High resolution airborne laser data provide new ways to explore the role of topographic complexity in hydraulic modelling parameterisation, taking into account the scale-dependency between roughness and topography. In this paper, a complex topography from LiDAR is processed using a spatially and temporally distributed method at a fine resolution. The surface topographic parameterisation considers the sub-grid LiDAR data points above and below a reference DEM, hereafter named as topographic content. A method for roughness parameterisation is developed based on the topographic content included in the topographic DEM. Five subscale parameterisation schemes are generated (topographic contents at $0, \pm 5, \pm 10, \pm 25$ and $\pm 50 \mathrm{~cm}$ ) and roughness values are calculated using an equation based on the mixing layer theory (Katul et al., 2002), resulting in a co-varied relationship between roughness height and topographic content. Variations in simulated flow across spatial subscales show that the sub grid-scale behaviour of the 2-D model is not well-reflected in the topographic content of the DEM and that subscale parameterisation must be modelled through a spatially distributed roughness parameterisation. Variations in flow predictions are related to variations in the roughness parameter. Flow depth-derived results do not change systematically with variation in roughness height or topographic content but they respond to their interaction. Finally, subscale parameterisation modifies primarily the spatial structure (level of organisation) of simulated 2-D flow linearly with the additional complexity of subscale parameterisation.
\end{abstract}

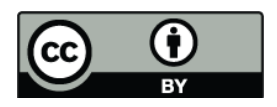

Correspondence to: A. Casas (angelescasasp@gmail.com)

\section{Introduction}

Roughness elements on a floodplain comprise both ground surface irregularities (i.e. topographic variability) and vegetation elements (trees, bushes, logs, stumps, etc.). A spatially distributed approach to any hydraulic modelling scheme must therefore be based on a map of these roughness elements over the floodplain at different scales. Theoretically, the topographic representation should characterise the terrain surface over which the fluid flows at an adequately discretised scale in order to reflect the flow processes of interest. Similarly, roughness parameterisation must account for energy losses due to geometric variability of the surface produced at scales finer than those represented in the mesh (discretisation scale). Clearly, both concepts are physically linked by a scale-dependency, which may strongly influence two-dimensional hydraulic modelling results (Nicholas, 2001; Horritt et al., 2006). A higher resolution model will explicitly encompass smaller topographic variations, provided the associated topographic data are at the same resolution and capture these well enough. With a coarser model resolution, smaller topographic variations will need to be parameterised, either explicitly through a porosity type treatment (e.g. Yu and Lane, 2006b) or upscaling of a roughness parameter (Clifford et al., 1992). The main problem of assessing spatial subscale effects upon flow is that, in practice, roughness parameterisation must account not only for discrepancies between the intrinsic scale of the surface variability and the scale represented in a mesh, but also for the discrepancies between the intrinsic scale of the flow process and the processes explicitly represented in the numerical solution (i.e. the processes not explicitly represented because of the averaging of the flow equations in time or space, such

Published by Copernicus Publications on behalf of the European Geosciences Union. 
as diffusive effects in flow due to turbulence in a 2-D approach). Therefore, the roughness parameter turns out to be an effective parameter commonly obtained through a calibration procedure (e.g. Lane and Ferguson, 2005; Hunter et al., 2007). This situation complicates the scale-dependent relationship between roughness and topography.

However, the growth of hydraulic modelling applications has emphasized the importance and necessity of innovation in terms of processes representation, mainly in relation to boundary roughness parameterisation (Lane et al., 2004; Nicholas, 2005; Horritt, 2005; Carney et al., 2006) and topographic parameterisation methodologies (Bates et al., 2003; Leclerc, 2005, Casas et al., 2010). This is particularly the case in the light of new possibilities for technical advances in remote sensing, topographic data collection and spatial analysis techniques. At the same time, the recent increasing availability of high resolution LiDAR data for representing complex surfaces in detail (Marks and Bates, 2000; Bates et al., 2003; Suarez et al., 2005; Andersen et al., 2006; Mandlburger and Briese, 2007; Liu, 2008; Cook and Merwade, 2009) and extracting vegetation density and height (Popescu and Zhao, 2008; Antonarakis et al., 2007, 2008) are promoting the development of new resistance formulations to link this highly detailed information with the spatially-averaged flow dynamics simulated by the model (Katul et al., 2002; Poggi et al., 2008, 2009). LiDAR measurement principles are well established (Ackermann, 1999; Wehr and Lohr, 1999) but the processing of raw data and the accuracy of resultant modelled data are not so evident (Gomes-Pereira and Wicherson, 1999; Hodgson and Bresnahan, 2004) although Marks and Bates (2000), Bates et al. (2003) and Mason et al. (2003) are important exceptions in relation to flood inundation modelling. Previous research on LiDAR applications to river hydraulics has addressed not only the influence of mesh resolution of processed laser data but that of the characteristic elements that modify the measurement scale, including the raw point density scheme and flying height in the measurement scale (Hirata, 2004), but also its particular impact upon flood modelling (Raber et al., 2003; Omer et al., 2003; Gueudet, 2004; Haile, 2005).

One of the main difficulties in the use of LiDAR data is the uncertainty introduced in the DEM, namely the errors due to the difficulty of filtering bare earth from the rest of measured data (e.g. Sithole and Vosselman, 2004). Low vegetation is particularly difficult to differentiate from ground measurement (Asselman, 2002; Straatsma and Middelkoop, 2006). Filtering procedures are commonly used to classify bare earth from the rest of the points. Different filtering and classification procedures or criteria will lead to different modelled ground surfaces for a certain mesh resolution (Sithole and Vosselman, 2004). Points classified as terrain will determine the topographic content of the ground model, which in combination with mesh resolution determines the spatial scale of the elevation model. Thus, high resolution laser altimetry data cannot only be extremely useful for the topographic parameterisation of a 2-D hydraulic model but also provide insight into the main set of problems related to scale in its spatial parameterisation (e.g. Hauer et al., 2009). LiDAR data can be used to control the topographic content introduced into a DEM generated for a fixed mesh resolution. In this way, the assessment of spatial scale effects in hydraulic models can be performed by modifying exclusively the topographic content of the DEM (Casas et al., 2010).

This paper explores the role of topographic complexity considering a spatially and temporally distributed subscale parameterisation, where the roughness parameterisation scheme varies with the amount of high resolution geometric detail included in the topographic DEM. The main objectives are Eq. (1) to develop a subscale spatial parameterisation methodology using LiDAR data that responds to the dependency of the model upon the topographic scale for a 2-D floodplain inundation model and Eq. (2) to assess its parameterisations' impacts upon the magnitude and the structure of depth derived results. It must be noted that a precise characterisation of hydraulic roughness values is outside the scope of this study, and would require detailed field recording of hydraulic variables (discharge, depth, velocity, etc.) during a flood. A major contribution of this study is to account for the impact of topographic complexity below the scale of the model upon simulated flow taking advantage of the high resolution geometric detail provided by LiDAR mapping sources. Our approach allows us: Eq. (1) to consider the topographic scale dependence in a distributed roughness parameterisation method; and Eq. (2) to separate the impact of the amount of topography included in the DEM at a certain modelling scale without introducing mesh resolution scaling impacts. Mesh resolution impacts upon subscale parameterisation will be on the scope of further research in relation to the topographic impact across modelling scales.

\section{Methodology}

Our approach considers that the spatial scale of discretisation in the inundation model should act as a threshold for the relative topographic and roughness parameterisation. Therefore, the roughness height $\left(z_{0}\right)$ can be determined as a function of the amount of topography (i.e. the topographic content, $\Delta z$ ) contained within the discretised mesh, which conversely depend on the mesh resolution $(m)$ of topographic and roughness parameterisation. Hence, the topographic and roughness parameterisation should be connected through a threeway interaction between the mesh resolution, topographic content and the roughness parameterisation.

\subsection{Digital terrain modelling and topographic content}

The study reach comprises a $2 \mathrm{~km}$ reach of the Ter River (NE Spain) characterised by a low sinuosity meandering river channel morphology, with alternate gravel bars. The channel banks and nearby floodplain areas are stabilised by a dense 


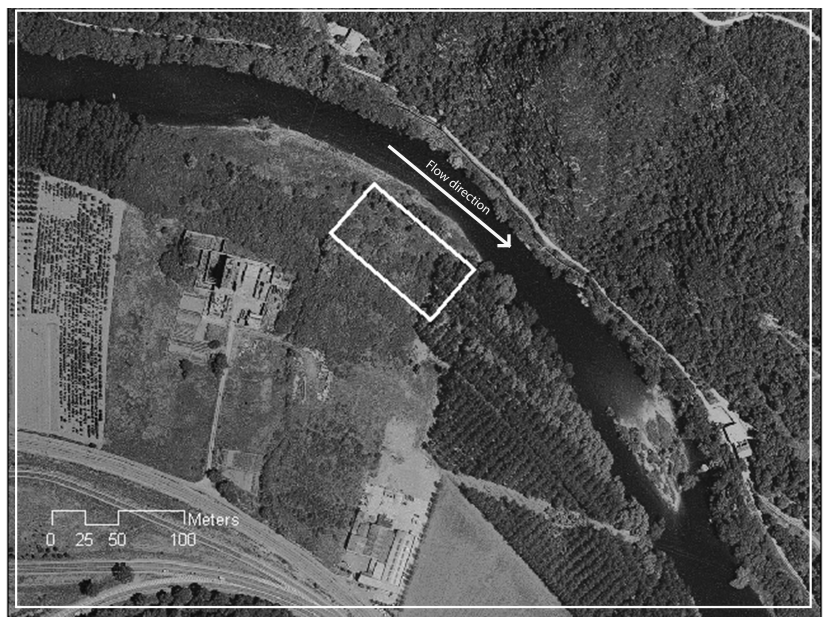

Fig. 1. Ortophoto with the location of the modelled reach (large rectangle) and the detailed rectangle on the floodplain of the Ter River, near Sant Julià de Ramis (Girona, NE Spain).

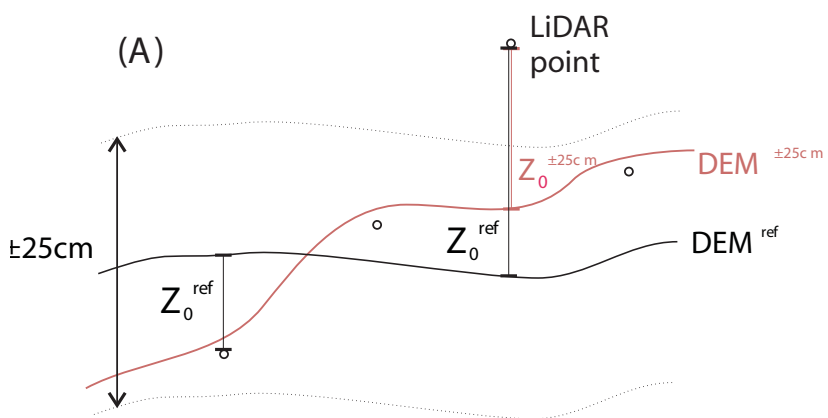

(B)

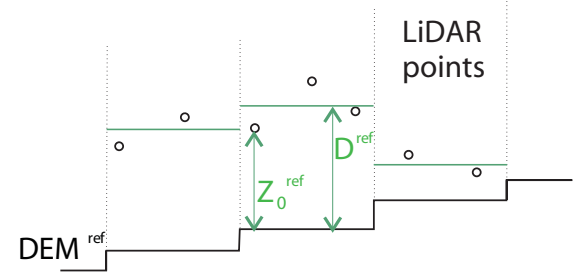

Fig. 2. (A) Selection criteria for the incorporation of a LiDAR point within the topographic or roughness parameterisation procedure. (B) Cell roughness calculation of averaged roughness height $(D)$ for a representation scale.

riparian vegetation, whereas most of the floodplain is occupied by field crops (cereals and alfalfa) and plots with poplar groves. For our purpose, a quadrilateral of $100 \mathrm{~m}$ by $50 \mathrm{~m}$ from the floodplain area was selected (Fig. 1). The selected area contains an array of vegetation types, including riparian vegetation (with different heights), poplar planted groves and crops.
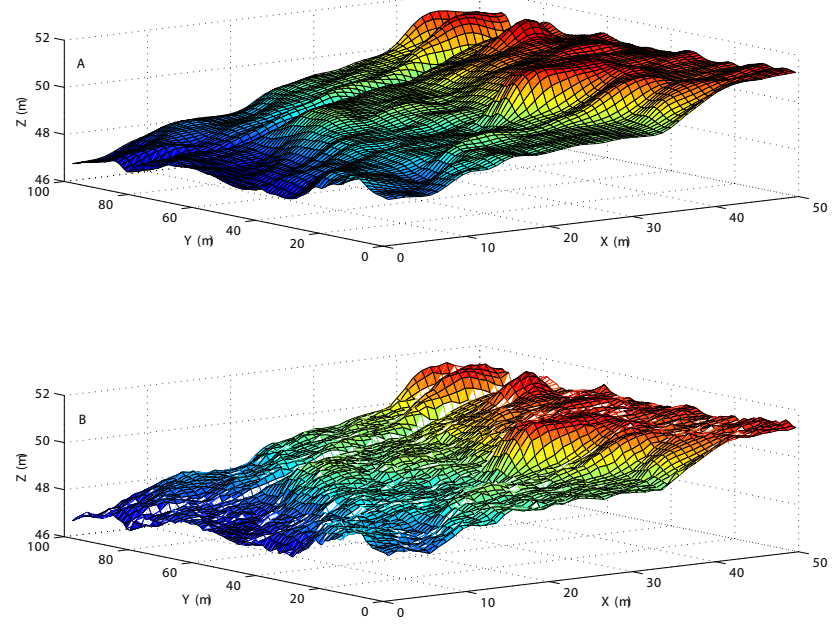

Fig. 3. Generation of DEMs with additional topographic information. (A) Reference DEM, (DEM ${ }^{\text {ref }}$ ); (B) DEM with additional topographic content of $\pm 25 \mathrm{~cm}\left(\mathrm{DEM}^{ \pm 25 \mathrm{~cm}}\right)$. The origin of the plot corresponds to the corner of the detailed rectangle in Fig. 1, which is downstream and closer to the river bank.

The initial DEM was generated with LiDAR data (1 point per $\mathrm{m}^{2}$ ), previously classified as ground data using the TerraScan software (Terrasolid, 2001). Ground points were then interpolated into a raster model of $1 \mathrm{~m}$ cell size. A low pass filter was used to generalise the model and to remove or to reduce local detail. The "low pass" filter operates by moving a window of $3 \times 3$ across the entire raster and the new value for the cell at the centre of the window is a weighted average of the values in the window. The resultant DEM was a smoothed generalised version of the topographic surface for a mesh resolution of $1 \mathrm{~m}$ (referred to as DEM $^{\text {ref }}$ ). LiDAR elevation points were progressively added to increase the amount of topographic complexity to DEM $^{\text {ref }}$ (i.e. more LiDAR elevation points). This is achieved using a vertical variability threshold criterion (see Fig. 2a), i.e. when the distance between the reference DEM (Fig. 3a) and the point to be added is within the vertical (e.g. $\pm 25 \mathrm{~cm}$ ) threshold, the point is selected to be incorporated in the DEM (e.g. DEM $\pm 25 \mathrm{~cm}$ ), (Fig. 3b). Four vertical variability thresholds are used, $\pm 5 \mathrm{~cm}, \pm 10 \mathrm{~cm}, \pm 25 \mathrm{~cm}, \pm 50 \mathrm{~cm}$, providing four different sets of data containing topographic content with different levels of complexity. By sampling from the point cloud, this approach retains the spatial correlation of elevation data as measured in the original LiDAR data. The sampled data were combined with the data in $\mathrm{DEM}^{\text {ref }}$ to create a Topographical Irregular network (TIN) structure that was then interpolated into a raster model of $1 \mathrm{~m}$ mesh cell size. Therefore, five DEMs are generated, the reference one $\left(\mathrm{DEM}^{\mathrm{ref}}\right)$ and four with additional topographic content $( \pm \Delta z), \mathrm{DEM}^{ \pm 5 \mathrm{~cm}}, \mathrm{DEM}^{ \pm 10 \mathrm{~cm}}, \mathrm{DEM}^{ \pm 25 \mathrm{~cm}}$, $\mathrm{DEM}^{ \pm 50 \mathrm{~cm}}$ (Casas et al., 2010). These DEMs have different topographic contents, the increase of the vertical threshold 


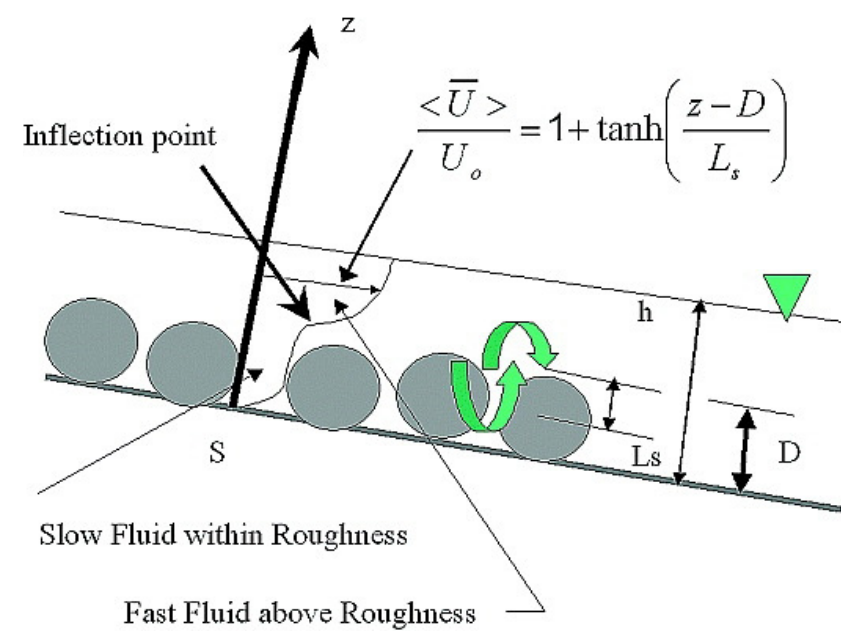

Fig. 4. Onset of free shear turbulent flows in shallow streams, after Katul et al., 2002.

of LiDAR data will produce DEMs with greater height variability which can be quantified using spatial statistics. In this study, the semivariance and Geary's C spatial autocorrelation index (Cliff and Ord, 1973) are used.

\subsection{Roughness parameterisation}

LiDAR-derived roughness height $\left(z_{0}\right)$ values for each cell of the modelled surface permits an objective estimation of the flow resistance for each cell of the 2-D floodplain inundation model. This study uses a new mixing layer theory for flow resistance in shallow streams developed by Katul et al. (2002). This approach predicts flow resistance from surface roughness measures and water depth using a mixing layer analogy rather than the standard rough-wall boundary layer theory. The mixing layer theory with its inflectional profile yields mean flow velocities at high relative roughness, providing analytical linkage between depth, roughness, and velocity for $h / z_{0}<7$ where $h$ is water depth and $z_{0}$ roughness height.

The approach makes use of the turbulent flow structure within and above rigid vegetation canopies. The structure of the flow near extensive and porous roughness elements resembles a mixing layer with an inflection near the mean height of the roughness element (D), Fig. 4, (Raupach et al., 1996, cited by Katul et al., 2002) whereas rough-wall boundaries do not possess an inflection point (Katul et al., 2002).

The theory acknowledges that the mean velocity within the roughness element is small, while above the roughness element the mean velocity is large. Inflectional profiles are reproduced using a mean velocity equation given by:

$\frac{\bar{U}}{U_{0}}=1+\tanh \left(\frac{z-D}{L_{s}}\right)$

where $D$ is the mean height of the roughness elements; $L_{S}$ is a characteristic energetic eddy size (i.e., mixing length) produced at $z=D$ and $U_{0}$ is the mean reference velocity at $z=D$. Following Katul et al. (2002), the depth-averaged velocity can result, for $L_{s} \approx \alpha D$ :

$$
\begin{aligned}
\frac{U}{u_{0}} & =\frac{1}{h} \int_{0}^{h}\left[1+\tanh \left(\frac{z-D}{\alpha D}\right)\right] d z \\
& =1+\frac{\alpha D}{h} \ln \left(\frac{\cosh \left(\frac{1}{\alpha}-\frac{h}{\alpha D}\right)}{\cosh \left(\frac{1}{\alpha}\right)}\right)
\end{aligned}
$$

By letting: $u_{0}=C_{u} u_{*} ; \xi=\frac{h}{D}$;

$f(\xi, \alpha)=1+\alpha \frac{1}{\xi} \ln \left(\frac{\cosh \left(\frac{1}{\alpha}-\frac{1}{\alpha} \xi\right)}{\cosh \left(\frac{1}{\alpha}\right)}\right)$

It can be expressed as:

$\frac{U}{u_{*}}=C_{u} f(\xi, \alpha)$

where $C_{u}$ is a similarity constant and $u_{*}$ is the friction velocity:

$u_{*}=\sqrt{g, h, S}$

where $S$ is the bed slope and $h$ the depth

The result in Eq. (4) is highly dependent on the definition of $D$. Upon comparing Eqs. (4) and (5) and Manning's equation for a wide rectangular channel:

$U=\frac{1}{n} h^{2 / 3} S^{1 / 2}$

a relation between the depth-averaged velocity and Manning's $n$ can be explicitly established:

$n=\frac{h^{1 / 6}}{\sqrt{g C_{u} f(\xi, \alpha)}}$

Values of $\alpha=1$ and $C_{u}=4.5$ are recommended for a range of $h / D$ of between 0.2 and 7 .

In this study, this equation incorporated into the 2-D flood model and a roughness value is obtained for each cell of the domain at every time step of the calculation. The mean height of the roughness element $(D)$ is set to be the averaged value of the roughness height $\left(z_{0}\right)$ data located within a cell of the model mesh, where $z_{0}$ is calculated as the difference between the DEM and measured LiDAR point, (see Fig. 2b). Thus, the definition of $D$, and therefore $n$, will depend upon the mesh resolution of the scheme. Therefore, the modelling scheme of the 2-D hydraulic model applied in this study requires a Digital Roughness Model (DRM) with $D$ values as the mean height of the roughness heights $\left(z_{0}\right)$ contained within the cell (see Fig. 2b). The DRM at a given mesh resolution, along with the local water depth are required to provide a spatio-temporally varying parameterisation of surface friction in the flood model. 
The methodology developed in this study to obtain a distributed roughness parameterisation is based on roughness height information $\left(z_{0}\right)$ of non-terrain elements derived from LiDAR points recorded but not classified and thus not included in the terrain model generation as topographic content $(\Delta z)$, (see Fig. 2a). Therefore, using this scheme, roughness height $\left(z_{0}\right)$ estimation will be dependent on the topography used to generate the DEM and its mesh resolution. Where the DEM does not represent topography explicitly, the model accounts for it through the roughness height $\left(z_{0}\right)$.

Roughness height calculation uses LiDAR altimetric data to which the elevation of the DEM is subtracted using a GIS routine (e.g. Cobby et al., 2001). The resultant roughness height $\left(z_{0}\right)$, which is the measured LiDAR data detrended from the terrain elevation (Fig. 5), was then interpolated to the corresponding mesh resolution $(m)$ of the DEM into a DRM.

In this approach, it is assumed that the laser measures the range to any obstacle, which subsequently disturbs the flow pattern at a specific location. Thus, momentum roughness height ( $z_{0}$ or the height at which velocity becomes zero) is considered to be the difference between the height at which the laser find the higher physical solid obstacle and the estimated terrain height at that location.

\subsection{Hydraulic modelling}

In this study, a hybrid 1-D/2-D hydraulic model (FloodMap) of flood inundation has been used. FloodMap (Yu and Lane, 2006a, b) is a coupled 1-D/2-D flood inundation model designed for fluvial flood inundation prediction in topographically complex floodplains. It has a similar structure to that of JFLOW (Bradbrook et al., 2004). The model is the basis of the sub-grid treatment approach developed by $\mathrm{Yu}$ and Lane (2006b) and has been tested and verified with a range of boundary conditions and in a number of environments (Yu, 2005; Tayefi et al., 2007; Lane et al., 2007; Lane et al., 2008). Yu and Lane (2006a) have reviewed the basis of the model, and so only the major model structure is outlined here. The coupled model assumes that the floodplain is protected by an embankment that essentially acts as a continuous, broad-crested weir through which flow exchange occurs between the channel and floodplain. A tightly-coupled approach solves the one-dimensional river flow and twodimensional floodplain flows simultaneously in a raster environment. The one-dimensional in-channel model solves the full Saint-Venant equations for unsteady open-channel flow using the Preissmann scheme based upon the fixed bed model of Abbott and Basco (1989).

The floodplain flow is simulated with a 2-D diffusionbased approach based on the discretisation of the Manning's equation in a raster-based environment. The model is topography driven, and recognizes any change in topographic modelling scale in terms of small-scale flow characteristics

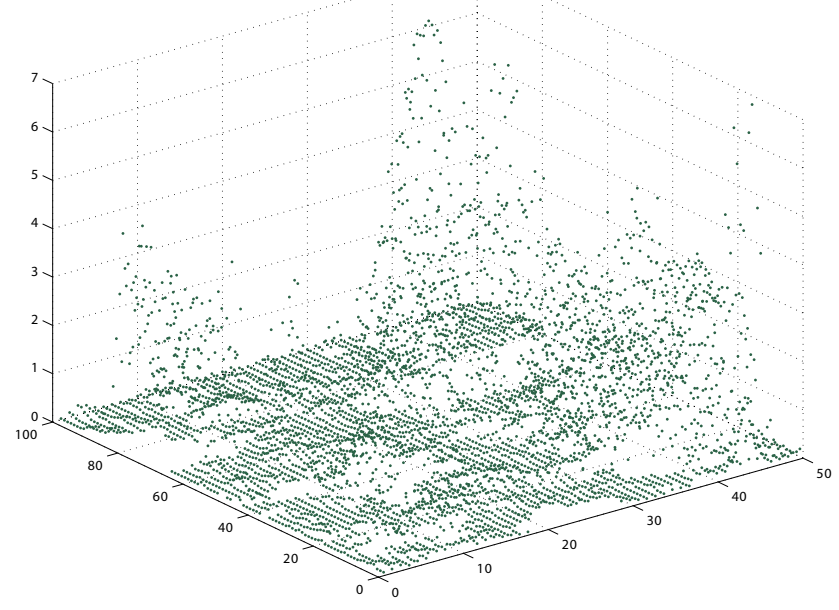

Fig. 5. Detrended roughness heights for the $1 \mathrm{~m}$-resolution reference DEM studied floodplain detail, $(\mathrm{m})$. The origin of the plot corresponds to the corner of the detailed rectangle in Fig. 1, which is downstream and closer to the river bank.

and routing, water surface elevation and large-scale inundation extent.

\subsection{Model boundary conditions}

Three types of boundary conditions are required by the 1-D component of FloodMap, i.e. upstream and downstream flow hydrographs, river cross sectional geometry, and roughness parameter in each cross section. In terms of the flow boundary conditions, FloodMap can use a combination of either: (i) velocity downstream and stage upstream; or (ii) velocity upstream and stage downstream In addition, both options require an estimation of water depth and velocity at each crosssection at the start of simulation, as initialisation data. This is summarized in Table 1. For this application, the second option is used.

There were no measured flow boundary conditions available at the domain boundary of the study site to initialize the 1-D component of FloodMap. Instead, these were obtained from a one-dimensional hydraulic HEC-RAS model (Reference of Army Corps of Engineers) implemented along a $2 \mathrm{~km}$ long river reach run for subcritical flow conditions (Casas et al., 2006). The associated water depth and velocity used here are shown in Table 2. For this reach, the flow boundary conditions required by FloodMap were calculated with an initial discharge of $25 \mathrm{~m}^{3} \mathrm{~s}^{-1}$.

A simple cross section geometry of a rectangular shape is used in this study. For each cross-section, channel width and depth are required to represent the cross section geometry. These were calculated with cross-section GPS coordinates obtained from field survey. For the 1-D model, Manning's $n$ coefficients at each cross section at the simulation domain were obtained through a calibration process from the 
Table 1. Boundary condition requirements for the 1-D river model. (Option 2 is used in this study).

\begin{tabular}{lcccccc}
\hline depth & $\begin{array}{c}\text { Upstream } \\
\text { depth }\end{array}$ & $\begin{array}{c}\text { Downstream } \\
\text { velocity }\end{array}$ & $\begin{array}{c}\text { Upstream } \\
\text { velocity }\end{array}$ & $\begin{array}{c}\text { Downstream } \\
\text { cross-section }\end{array}$ & $\begin{array}{c}\text { Depth at each } \\
\text { cross-section }\end{array}$ & Velocity at each \\
\hline Option 1 & $\sqrt{ }$ & & & $\sqrt{ }$ & $\sqrt{ }$ & $\sqrt{ }$ \\
Option 2 & & $\sqrt{ }$ & $\sqrt{ }$ & & $\sqrt{ }$ \\
\hline
\end{tabular}

Table 2. Inflow data.

\begin{tabular}{cccc}
\hline Time (h) & $\begin{array}{c}\text { Discharge } \\
\left(\mathrm{m}^{3} \mathrm{~s}^{-1}\right)\end{array}$ & $\begin{array}{c}\text { Depth }(\mathrm{m}) \\
\text { downstream }\end{array}$ & $\begin{array}{c}\text { Velocity }\left(\mathrm{ms}^{-1}\right) \\
\text { upstream }\end{array}$ \\
\hline 0 & 25 & 1.09 & 0.69 \\
1 & 1000 & 4.93 & 2.81 \\
2 & 2000 & 7.26 & 3.18 \\
3 & 1000 & 4.93 & 2.81 \\
4 & 1000 & 4.93 & 2.81 \\
5 & 1000 & 4.93 & 2.81 \\
6 & 1000 & 4.93 & 2.81 \\
\hline
\end{tabular}

HEC-RAS modelling (Casas et al., 2006). In total thirteen cross sections were used in the study site. The associated boundary conditions required by the model are shown in Table 3 . These boundary conditions are introduced in the model as ASCII files.

The model was run for the whole floodplain area for each DEM and the associated digital roughness model (DRM). Two-dimensional velocities and water surface elevation ASCII files were obtained for each simulation.

\subsection{Characterisation of topography and modelled flow fields}

The level of organisation of the DEMs and simulated flow according to the topographic content or the roughness parameterisation is quantified using spatial statistics. The semivariance statistic, which uses the squared differences between neighbouring pixel values, provide an idea of the vertical variability underlying each surface for a certain lag. A lag of 1 pixel has been selected, as it is the mesh resolution of DEMs, therefore each pixel is evaluated against its immediate neighbour. Semivariance values quantify the increment in the variability of the DEM as the vertical threshold $\Delta z$ of input data are increased (i.e. its topographic content)

Spatial autocorrelation, using Geary's C index, has also been calculated for the scaled DEMs to quantify the homogeneity in the spatial pattern of each DEM through the comparison of neighbouring pixel values. Geary's C uses the formula:

$$
\mathrm{C}(d)=\frac{(n-1) \sum_{i}^{n} \sum_{j}^{n} w_{i j}\left(y_{i}-y_{j}\right)^{2}}{2 W \sum_{i}^{n} z_{i}^{2}}
$$

Where $w_{i j}$ is the weight at distance $d$, $z$ 's are deviations from the mean for variable $y$, and $W$ is the sum of all the weights where $i \neq j$. The value ranges from 0.0 to 3.0, with 0.0 for a strong positive spatial autocorrelation and +1 for no correlation. Values from 1.0 to 3.0 indicate negative correlation.

\section{Results}

Firstly, the distributed roughness parameterisation methodology developed is evaluated and the topographic content of DEMs is quantified. Secondly, scaling effects upon hydraulic model results due to roughness parameterisation and variations in the topographic content of the DEM are assessed. Thereafter, the topographic content impact is isolated and the level of organisation of depth results is quantified through the Geary's C spatial autocorrelation index Eq. (8). Finally, the full area is considered and model results are evaluated.

Descriptive statistics and semivariance values for each DEM are summarized in Table 4. Semivariance values increase as the models comprise more topographic content for a fixed mesh resolution. In addition, the spatial autocorrelation Geary's C index Eq. (8) has been calculated to compare the homogeneity between these DEMs as topographic content is introduced. Table 4 shows that Geary's C spatial autocorrelation index increases as larger topographic content is introduced.

Table 5 summarises the statistics of roughness parameterisation ( $n$, from Eqs. 2 and 3 ) for the 2nd and 4th h of the simulation according to each scaled scheme for the detailed studied floodplain area. The Table shows that the Manning's $n$ parameter does not vary systematically with any of scaled schemes but according to an interaction between topography and, therefore, depth and roughness height. As expected, the mean roughness parameter, and its standard deviation, decreases from the second hour to the fourth hour. It must be noted that these scaled topographies are constructed for a constant mesh resolution which is known to have a large impact in cellular-based approaches (e.g. Yu and Lane, 2006a; Hunter et al., 2007). 
Table 3. Model geometry and boundary conditions estimated for an initial discharge of $25 \mathrm{~m}^{3} \mathrm{~s}^{-1}$.

\begin{tabular}{ccccccc}
\hline XS-ID & $\begin{array}{c}\text { width } \\
(\mathrm{m})\end{array}$ & $\begin{array}{c}\text { length } \\
(\mathrm{m})\end{array}$ & $\begin{array}{c}\text { bed elevation } \\
(\mathrm{m})\end{array}$ & $\begin{array}{c}\text { Manning's } \\
n\end{array}$ & $\begin{array}{c}\text { mean velocity } \\
\left(\mathrm{m}^{2} \mathrm{~s}^{-1}\right)\end{array}$ & $\begin{array}{c}\text { depth } \\
(\mathrm{m})\end{array}$ \\
\hline 0 & 41,86 & 31,38 & 44,88 & 0,00 & 0,69 & 1,43 \\
1 & 53,01 & 90,05 & 44,91 & 0,10 & 0,49 & 1,40 \\
2 & 56,18 & 151,64 & 44,88 & 0,11 & 0,46 & 1,41 \\
3 & 48,96 & 88,12 & 44,90 & 0,04 & 0,44 & 1,36 \\
4 & 43,04 & 159,17 & 44,85 & 0,02 & 0,46 & 1,40 \\
5 & 41,93 & 96,00 & 44,90 & 0,09 & 0,68 & 1,26 \\
6 & 71,42 & 135,08 & 44,91 & 0,07 & 0,66 & 1,21 \\
7 & 73,79 & 52,49 & 44,89 & 0,03 & 0,56 & 1,19 \\
8 & 66,48 & 61,73 & 44,88 & 0,04 & 0,73 & 1,12 \\
9 & 55,13 & 124,05 & 44,84 & 0,07 & 0,52 & 1,09 \\
10 & 61,84 & 125,66 & 44,86 & 0,09 & 0,54 & 1,00 \\
11 & 91,80 & 157,86 & 44,81 & 0,02 & 0,51 & 0,99 \\
12 & 90,67 & 25,28 & 44,37 & 0,09 & 0,85 & 1,29 \\
13 & 50,02 & 25,00 & 44,39 & 0,03 & 1,44 & 1,09 \\
\hline
\end{tabular}

Table 4. Descriptive statistics for each scaled DEM.

\begin{tabular}{llllll}
\hline Statistics & $\mathrm{DEM}^{\text {ref }}$ & $\mathrm{DEM}^{ \pm 5 \mathrm{~cm}}$ & $\mathrm{DEM}^{ \pm 10 \mathrm{~cm}}$ & $\mathrm{DEM}^{ \pm 25 \mathrm{~cm}}$ & $\mathrm{DEM}^{ \pm 50 \mathrm{~cm}}$ \\
\hline Mean (m) & 53.386 & 53.386 & 53.387 & 53.392 & 53.399 \\
Minimum (m) & 44.445 & 44.445 & 44.445 & 44.393 & 44.393 \\
Maximum (m) & 75.609 & 75.609 & 75.609 & 75.609 & 75.609 \\
Std. Dev. (m) & 2.896 & 2.896 & 2.896 & 2.897 & 2.896 \\
Semivariance (m) & 0.000159 & 0.000159 & 0.00016 & 0.000168 & 0.000183 \\
Geary's C & 0.00376 & 0.00377 & 0.00385 & 0.00446 & 0.00562 \\
\hline
\end{tabular}

Figure 6 shows, for the detailed studied floodplain area (Fig. 1), the input data (roughness heights (Fig. 6a) and model derived depths (Fig. 6b) required to calculate the distributed roughness parameter $n$ (Fig. 6c). Roughness heights and roughness parameter are correlated (Fig. 6) where Manning's $n$ values vary from 0.036 to 0.25 for a range of $0.02-$ $5.6 \mathrm{~m}$ of roughness heights,. This is confirmed in Table 5 where correlation coefficient $(r)$ of Manning's $n$ parameter in relation to roughness height $\left(z_{0}\right)$ and topographic elevation $(\mathrm{DEM})$ is calculated as a measure of the agreement between model components.
Once the behaviour of the roughness methodology has been studied, interactions in the model performance between distributed roughness heights $\left(z_{0}\right)$ and DEMs with different topographic content $( \pm \Delta z)$ can be assessed for our detailed floodplain area (see Fig. 1). Figure 7 represents the impact (RMSD) on roughness parameterisation (Fig. 7a) and depth derived results (Fig. 7b) for a detailed floodplain area at the 2 nd and 4 th h of the simulation. The impact of additional subscale complexity $( \pm 5, \pm 10, \pm 25$ and \pm 50$)$ in the model upon both roughness parameterisation and depth derived results decreases towards the 4th h (Fig. 7). Figure $7 \mathrm{a}$ shows the comparison (RMSD) between roughness parameterisations obtained using Eq. (7) that the impact 
Table 5. Statistics of roughness parameter $(n)$ due to variations in the topographic content of the DEM $(\Delta z)$ and the roughness height $\left(z_{0}\right)$ of the DRM for a detailed area (Fig. 1).

\begin{tabular}{clllll}
\hline & $n^{\text {ref }}(2 \mathrm{~h})$ & $n^{5 \mathrm{~cm}_{(2 h}}$ & $n^{10 \mathrm{~cm}}(2 \mathrm{~h})$ & $n^{\left.25 \mathrm{~cm}_{(2 h}\right)}$ & $n^{50 \mathrm{~cm}}(2 \mathrm{~h})$ \\
\hline mean & 0.072 & 0.075 & 0.072 & 0.074 & 0.072 \\
max & 0.260 & 0.259 & 0.260 & 0.259 & 0.260 \\
min & 0.034 & 0.030 & 0.035 & 0.033 & 0.034 \\
std. dev. & 0.050 & 0.054 & 0.049 & 0.052 & 0.050 \\
$r\left(z_{0}\right)$ & 0.882 & 0.849 & 0.884 & 0.867 & 0.875 \\
$r(\mathrm{DEM})$ & 0.459 & 0.490 & 0.455 & 0.474 & 0.460 \\
\hline & $n^{\text {ref }}(4 \mathrm{~h})$ & $n^{5 \mathrm{~cm}}(4 \mathrm{~h})$ & $n^{10 \mathrm{~cm}}(4 \mathrm{~h})$ & $n^{25 \mathrm{~cm}}(4 \mathrm{~h})$ & $n^{50 \mathrm{~cm}}(4 \mathrm{~h})$ \\
\hline mean & 0.067 & 0.068 & 0.067 & 0.068 & 0.067 \\
max & 0.260 & 0.260 & 0.259 & 0.260 & 0.260 \\
min & 0.038 & 0.037 & 0.038 & 0.038 & 0.038 \\
std. dev. & 0.041 & 0.043 & 0.041 & 0.042 & 0.041 \\
$r\left(z_{0}\right)$ & 0.930 & 0.923 & 0.931 & 0.927 & 0.929 \\
$r(\mathrm{DEM})$ & 0.389 & 0.402 & 0.387 & 0.395 & 0.387 \\
\hline
\end{tabular}
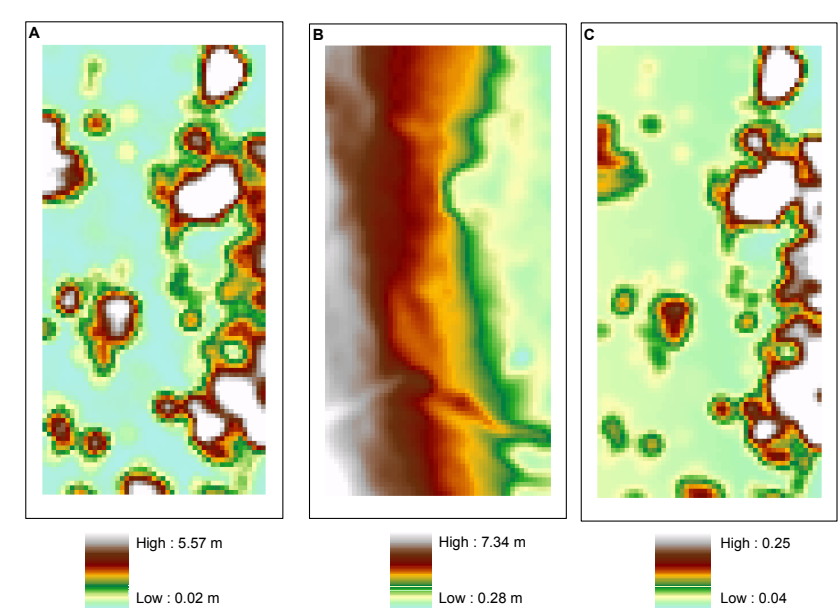

Fig. 6. (A) Input map of roughness heights for a $1 \mathrm{~mm}$ resolution of detailed area. (B) Model estimated depths at the second hour. (C) Derived hydraulic roughness map calculated by the model at the second hour.

is not systematic with the linear increment of the topographic subscale complexity that results from variation in the topographic content of the DEM and roughness height. Therefore, the roughness parameterisation model is sensitive to interactions between distributed roughness height and topographic content. The distributed scale-dependent methodology comprises the interaction between topography and roughness. Figure $7 \mathrm{~b}$ shows, the comparison (RMSD) between flow depth results using models with additional
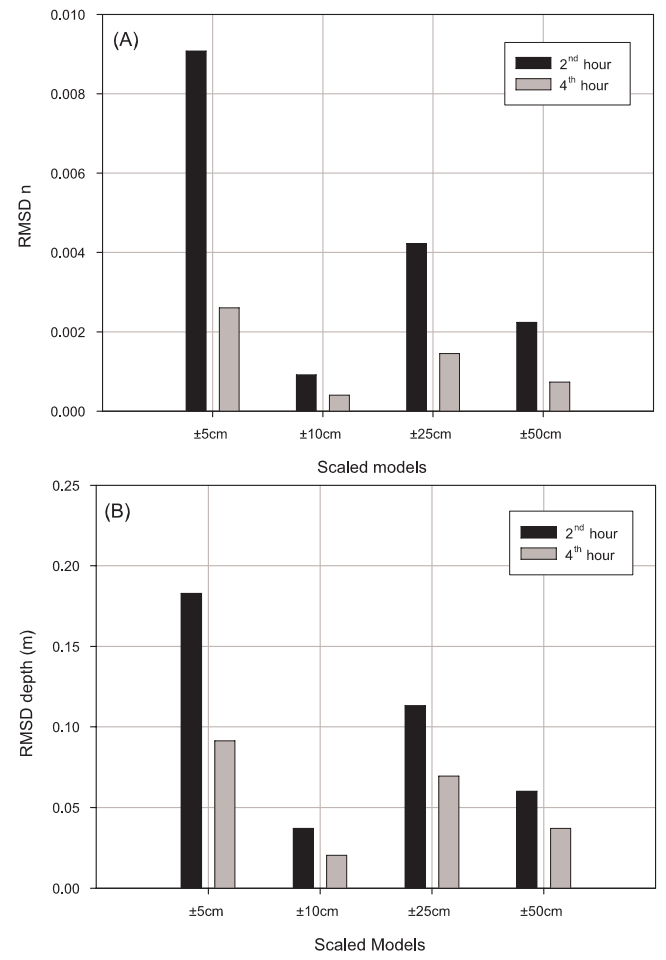

Fig. 7. RMSD values for (A) the roughness parameter and (B) depth derived results when different subscale scheme results $( \pm 5, \pm 10$, $\pm 25, \pm 50 \mathrm{~cm}$ ) are compared with those obtained using a reference scheme (Ref), for the 2 nd and 4 th $\mathrm{h}$ of the simulation. 


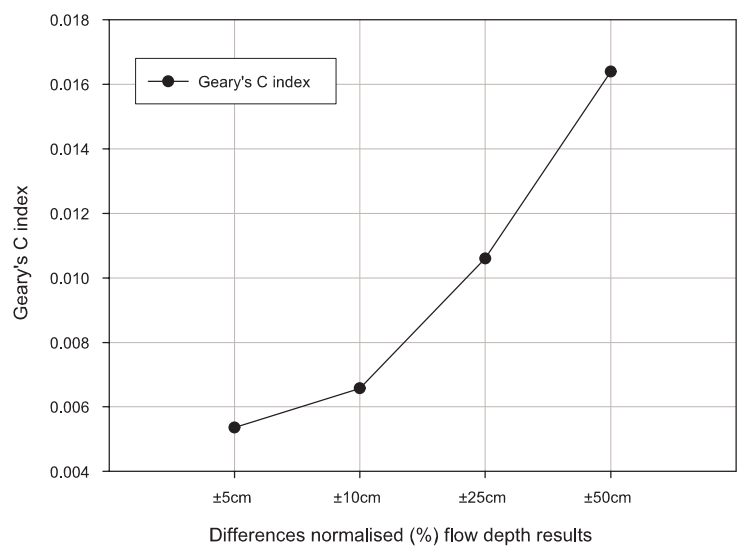

Fig. 8. Geary's autocorrelation spatial index the percentages of differences normalised of flow depth results using each scheme compared with those obtained using a reference one (Ref).

subscale complexity $( \pm 5, \pm 10, \pm 2$ 5and \pm 50$)$ with those obtained using a reference one without additional complexity (Ref). The figure shows that the impact is not systematic with the linear increment of the topographic subscale complexity. However, from the comparison of Fig. $7 \mathrm{a}$ and $\mathrm{b}$, it can be noted that variations (RMSD) in flow depth results are systematic with variations (RMSD) in roughness parameterisation.

The percentages of the normalised differences of the depth derived results using each scaled scheme in relation to the reference one (DEM $\left.{ }^{\text {ref }}\right)$ and the Geary's C spatial autocorrelation index have been calculated. Figure 8 shows how, as the spatial subscale scheme becomes more complex and from $\pm 5 \mathrm{~cm}$ toward $\pm 50 \mathrm{~cm}$, the autocorrelation index is closer to 1 , which implies lower organisation in the flow. Figure 9 corroborates visually this impact on the structure of the flow, where it is shown how for the subscale scheme (i.e. accounting for more topographic variation at $\pm 50 \mathrm{~cm}$ ) the flow is less organised (Fig. 9a).

In order to isolate the impact of the topographic content of the DEM, the model has been simulated for a constant value of roughness height of $0.02 \mathrm{~m}$, which results in a mean roughness value for the rectangle area of $0.043 \pm 0.004$ and $0.044 \pm 0.003$ at the $2 \mathrm{nd}$ and 4 th $\mathrm{h}$ of the simulation. This is calculated for each one of the five simulations with different topographic content in the DEM. Variations (RMSD) in depth results due to this constant roughness parameterisation are of $0,0.01,0.02$ and 0.03 when each model $( \pm 5 \mathrm{~cm}$, $\pm 10 \mathrm{~cm}, \pm 25 \mathrm{~cm}, \pm 50 \mathrm{~cm}$ ) is compared with the reference one. From these results, it can be stated that for a constant value of roughness height: (i) the roughness parameterisation is not globally sensitive to variations in the topographic content of the DEM; and (ii) the RMSD of depth varies positively, increasing with the increment of topographic content in the $1 \mathrm{~m}$-DEM, though in a very reduce quantity. Therefore, flow variability of the 2-D hydraulic model for a given

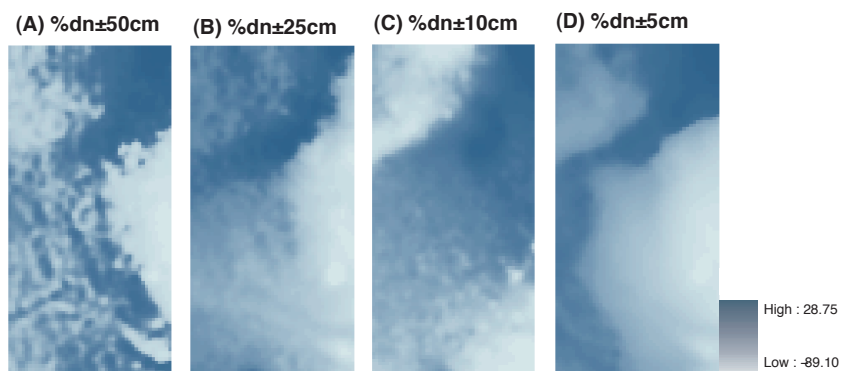

Fig. 9. Percentages of differences normalised of flow depth results using each subscale scheme, namely $\pm 50 \mathrm{~cm}$ (A), $\pm 25 \mathrm{~cm}$ (B), $\pm 10 \mathrm{~cm}$ (C), $\pm 5 \mathrm{~cm}$ (D) compared with those obtained using a reference one (Ref).

mesh resolution (close to measured topographic resolution) relies upon the interactions between topographic variability $(\Delta z)$ and roughness parameterisation $(n)$, the former with a stronger and non-linear impact.

Depth derived results obtained using a distributed roughness parameterisation have been compared (RMSD) with those model results obtained using the same roughness parameterisation methodology but a constant roughness height (Fig. 10). Figure 10 shows that the impact (RMSD) of using a constant or a distributed roughness parameterisation according to surface characteristics is larger than the impact of using one topographic model or another (Fig. 7b).

Finally, Table 6 summarises the roughness parameterisation impacts upon depth and inundation extent results at the 2nd and 4th $\mathrm{h}$ of the simulation for the full floodplain area. Variations (RMSD and percentage of differences normalised) are compared with the reference simulation results, showing a higher scaling effects on the inundation extent than on depth modelling results

\section{Discussion}

In river analysis, topography data and hydraulic roughness are major inputs to define terrain geometry.

Although scale dependency of roughness parameterisation upon represented topography is conceptually accepted, there are fewer studies quantifying the degree of this dependency (e.g. Lane, 2005; Horritt, 2005). Here we present a method to downscale topography using LiDAR geometric information and to include roughness content with physically meaningful criteria.

The blockage impact of downscaled complex topography is incorporated into the hydraulic scheme through a subscale parameterisation. The use of a mixing layer theory for flow resistance has allowed the calculation of a derived roughness parameter at each cell and for each time step of the modelling process. This formulation requires a mean roughness height of the protruding element, which has been calculated using high-resolution LiDAR data not included in 


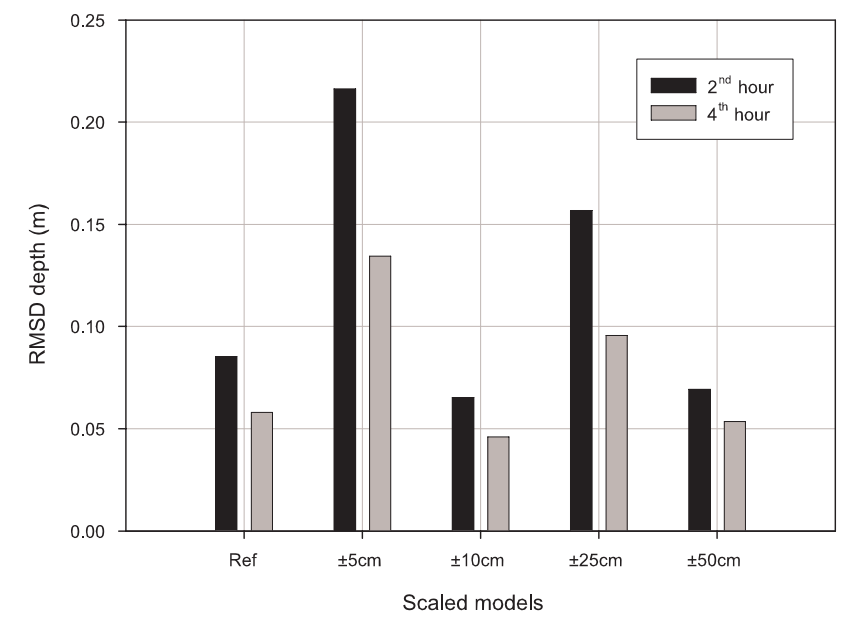

Fig. 10. RMSD values for depth derived results obtained with a distributed roughness parameterisation are compared with those obtained using a constant roughness height, for the 2 nd and 4 th $\mathrm{h}$ of the simulation.

the topographic model. The theory provides a neat analytical link between roughness and water depth and velocity, though it must be noted that ignores reduced resistance due to bending of vegetation and alignment of foliage with flow at higher velocities (Kouwen and Li, 1980; Kouwen and FathiMoghadam, 2000). The method encapsulates the three-way interaction between the discretised mesh resolution, the topographic content of the DEM and the roughness parameterisation and shows how subscale roughness parameterisation influence flood depth and inundation extent. Furthermore, this approach has provided a suitable method not only to quantify the roughness properties of the surface but also to test the sensitivity of the hydraulic parameters to a distributed roughness parameterisation approach versus a constant roughness value.

Downscaled analysis shows that variations in flow depth are systematic with variations in the subscale parameterisation and not in relation to the topographic content of the DEM. In fact, when a constant value of roughness height of $0.02 \mathrm{~m}$ (bare ground conditions) is applied, the subscale behaviour of the simplified 2-D raster based model is not well-reflected through the topographic content of the DEM. Therefore, subscale flow variations must be modelled through a spatially distributed roughness parameterisation that can retain small-scale topographic variations within coarse scale models. This implies the convenience of selecting an adequate model scale according to the computing and application demands of the hydraulic model given the low level impact of topographic variability within a certain mesh cell. It also emphasises the importance of including geometric shape details in the hydraulic computation mesh in accordance with some previous studies (Mandlburger et al., 2009; Schubert et al., 2008). This result may also play down the role of the filtering method used to classify ground points and
Table 6. Scaling effect upon depth derived results (RMSD) and inundation extent (differences normalised \%) due to subscale parameterisation for the full area at the 2 nd and 4 th $\mathrm{h}$ of the simulation, compared with the reference model $\left(\mathrm{DEM}_{1 \mathrm{~m}}^{\mathrm{ref}}\right)$ simulation results.

\begin{tabular}{lcccc}
\hline Scaled & \multicolumn{2}{c}{ RMSD Depth [m] } & \multicolumn{2}{c}{ Inundation extent [dn $\backslash \%]$} \\
Models & 2nd h & 4th h & 2nd h & 4th h \\
\hline DEM $^{\text {ref }}$ & 0.0000 & 0.0000 & 0.0000 & 0.0000 \\
$\mathrm{DEM}^{5 \mathrm{~cm}}$ & 0.0701 & 0.0490 & 0.4460 & 0.0060 \\
$\mathrm{DEM}^{10 \mathrm{~cm}}$ & 0.0548 & 0.0433 & -0.4700 & 0.3450 \\
$\mathrm{DEM}^{25 \mathrm{~cm}}$ & 0.0592 & 0.0433 & 0.0300 & 0.1940 \\
$\mathrm{DEM}^{50 \mathrm{~cm}}$ & 0.0634 & 0.0525 & 0.1360 & 0.0240 \\
\hline
\end{tabular}

its known problems in distinguishing between terrain points and low vegetation (Doneus and Briese, 2006) using rasterbased hydraulic models in rural areas, where only features at the model scale modify depth-derived results.

Our results show that parameterisation process not only influences depth and flood extent but also the structure of the depth derived results. Figure 9 depicts the importance of the topographic variability bellow the modelling scale upon the level of organisation of spatially distributed hydraulic results. The main implication of this sub-scale variation upon flow complexity results, according to the complexity of the spatial subscale scheme, is that a distributed subscale parameterisation impacts not only on the range of depth results, as the global RMSD values show, but also modify the characteristic scale of flow results. This variation on the level of organisation of modelled flow, as controlled by the down scaled topography at a given mesh resolution, may be important for some ecological applications, such as habitat availability where the river geometry at different scales plays a decisive role (Hauer et al., 2008; Lane and Carbonneau, 2007). In addition, this analysis emphasises the need for more comprehensive consideration of the impact of scale on dominant processes and parameter sensitivity (Bates et al., 2005).

The current problem of an appropriate roughness parameterisation is unsolved as, particularly in 2-D schemes, the roughness parameter must account for not only floodplain vegetation impacts on flow but all momentum losses not explicitly accounted for in the hydraulic model. This fact makes an upscaling necessary although this remains uncertain (Schubert et al., 2008; Straatsma and Baptist, 2008; Horritt et al., 2006; Lane, 2005; Mason et al., 2003). Hitherto, the low impacts on flood depths of any distributed roughness parameterisation (e.g. Mason et al., 2007) do not encourage the extra cost of additional multi-spectral data (Straatsma and Baptist, 2008), and also the time demands of featuring a height based resistance scheme to identify flow resistance coefficients and its further model validation with physical realistic values (Schubert et al., 2008). 
The results obtained in this work agree with previous work in which distributed roughness can have a non-linear impact on flow results (Horritt et al., 2006; Nicholas, 2005). Importantly, this work identifies a change in the spatial structure of the flow according to the organisation of downscaled topography, improving the insight of the performance of the model in relation to the structure and level of organisation of derived results at the modelling scale. This is important not only to design the modelling scheme but in the validation process. Data chosen to validate a model should reflect what the model must predict (Lane et al., 2005), then the required detailed variability in model results or the spatial structure of available validation data can drive the scale choice of the topographic and roughness parameterisation and should be taken into account in the modelling process. Further development of this method should address validation with spatially distributed field data.

\section{Conclusions}

The spatial scale dependency of a 2-D raster-based diffusionwave model upon topographic subscale representation and parameterisation using a distributed spatially and temporally variable roughness parameterisation was assessed. This analysis was based on laser altimetry data (LiDAR) and spatial analysis methods. A methodology to generate a roughness parameterisation model within the hydraulic model has been developed using down-scaled topographic data. The method explicitly recognises the three-way interaction between the discretised mesh resolution and the topographic content in the DEM with the roughness parameterisation. Subscale parameterisation has been shown to impact depth and inundation extent derived results. The impact of using a constant or a distributed roughness parameterisation according to surface characteristics is larger than the impact of using one topographic model or another. Variations in flow results were found to be systematically related to variations in the roughness parameter. The subscale behaviour of the 2-D hydraulic model is not well-reflected through the topographic content of the DEM and subscale parameterisation must be modelled through a spatially distributed roughness parameterisation. Subscale parameterisation modifies primarily the spatial structure (level of organisation) of simulated 2-D flow linearly with the complexity of subscale parameterisation. This work suggests that a spatially distributed roughness parameterisation provides a control in its impact upon the spatial distribution of model-derived results, therefore, upon its scale. Furthermore, our approach can be applied to crossverify the accuracy of spatially distributed field data (e.g. water levels, flow velocity, depth) as well as to design a strategy on field measurements requirements for model validation. There is a clear need to merge these results with variations in the mesh resolution as it may also influence hydraulic modelling results.
Acknowledgements. The authors would like to thank the ICC (Institut Cartographic de Catalunya), especially Antonio Ruiz, for the provision of the LiDAR data used in this study. Finally, we are grateful to the reviewers, D. C. Mason and G. J.-P. Schumann, whose comments helped to improve the original manuscript.

Edited by: N. Verhoest

\section{References}

Abbott, M. B. and Basco, D. R.: Computational fluid dynamics, Longman Scientific and Technical with John Wiley \& Sons, New York, 1989.

Ackermann, F.: Airborne laser scanning - present status and future expectations, ISPRS J. Photogramm., 54, 64-67, 1999.

Anderson, E. S., Thompson, J. A., Crouse, D. A., and Austin, R. E.: Horizontal resolution and data density effects on remotely sensed LIDAR-based DEM, Geoderma, 132(3-4), 406415, doi:10.1016/j.geoderma.2005.06.004, 2006.

Antonarakis, A. S., Richards, K. S., and Brasington, J.: Objectbased land cover classification using airborne LiDAR, Remote Sens. Environ., 112, 2988-2998, 2008.

Antonarakis, A. S., Richards, K. S., Brasington, J., Bithell, M., and Muller, E.: Retrieval of vegetative fluid resistance terms for rigid stems using airborne LiDAR, J. Geophys. Res., 113, G02S07, doi:10.1029/2007JG000543, 2008.

Asselman, N. E.: Laser altimetry and hydraulic roughness of vegetation - further studies using ground truth, Technical report, Delft, 2002.

Bates, P. D., Marks, K. J., and Horritt, M. S.: Optimal use of highresolution topographic data in flood inundation models, Hydrol. Process., 17, 537-557, 2003.

Bates, P. D., Lane, S. N., and Ferguson, R. I.: Computational Fluid Dynamics modelling for environmental hydraulics, in: Computational Fluid Dynamics Applications in Environmental Hydraulics, edited by: Bates, P. D., Lane, S. N., and Ferguson, R. I., John Wiley \& Sons Ltd, 1-15, 2005.

Bradbrook, K. F., Lane, S. N., Waller, S. G., and Bates, P.: Two dimensional diffusion wave modelling of flood inundation using a simplified channel representation, JRBM, 2, 3, 1-13, 2004.

Carney, S. K., Bledsoe, B. P., and Gessler, D.: Representing the bed roughness of coarse-grained streams in computational fluid dynamics, Earth Surf. Proc. Land., 31, 736-749, 2006.

Casas, A., Benito, G., Thorndycraft, V. R., and Rico, M.: The topographic data source of digital terrain models as a key element in the accuracy of hydraulic flood modelling, Earth Surf. Proc. Land., 31(4), 444-456, 2006.

Casas, A., Lane, S. N., Hardy, R. J., Benito, G. and Whiting, P. J.: Reconstruction of subgrid-scale topographic variability and its effect upon the spatial structure of three-dimensional river flow, Water Resour. Res., 46, W03519, doi:10.1029/2009WR007756, 2010.

Cliff, A. D. and Ord, J. K.: Spatial Autocorrelation, Pion Limited, London, 1973.

Clifford, N. J., Robert, A., and Richards, K. S.: Estimation of flow resistance in gravel-bedded rivers: A physical explanation of the multiplier of roughness length, Earth Surf. Proc. Land., 17, 111126, 1992. 
Cobby, D. M., Mason, D. M., and Davenport, I. J.: Image processing of airborne scanning laser altimetry for improved river flood modelling, ISPRS J.Photogramm., 56(2), 121-138, 2001.

Cook, A. and Merwade, V.: Effect of topographic data, geometric configuration and modeling approach on flood inundation mapping, J. Hydrol., 377, 131-142, 2009.

Doneus, M. and Briese, C.: Digital terrain modelling for archaeological interpretation within forested areas using full-waveform laserscanning, in: The 7th International Symposium on Virtual Reality, Archaeology and Cultural Heritage VAST, edited by: Ioannides, M., Arnold, D., Niccolucci, F., and Mania, K., Zypern, 3612-3613, 2006.

Gomes-Pereira, L. M. and Wicherson, R. J.: Suitability of laser data for deriving geographical information: a case study in the context of management of fluvial zones, ISPRS J. Photogramm., 54(23), 105-114, 1999.

Gueudet, D.: The influence of post-spacing density of DEMs derived from LiDAR on flood modeling, Technical report, University of Texas at Austin, 2004.

Haile, A. T. and Rientjes, T. H. M.: Effects of LiDAR DEM resolution in flood modelling: A model sensitivity study for the city of Tegucigalpa, Honduras, in: ISPRS WG III/3, III/4, V/3 Workshop "Laser scanning 2005", Enschede, The Netherlands, 2005.

Hauer, C., Mandlburger, G., and Habersack, H.: Hydraulically related hydro-morphological units: description based on a new conceptual mesohabitat evaluation model (MEM) using LiDAR data as geometric input, River Res. Appl., 25, 29-47, 2009.

Hirata, Y.: The effects of footprint size and sampling density in airborne laser scanning to extract individual trees in mountainous terrain, ISPRS, 36(8), 102-107, 2004.

Hodgson, M. E. and Bresnahan, P.: Accuracy of airborne LiDARderived elevation: Empirical assessment and error budget, Photogramm. Eng. Rem. S., 70(3), 331-339, 2004.

Horritt, M. S. and Bates, P. D.: Effects of spatial resolution on a raster based model of flood flow, J. Hydrol., 253, 239-249, 2001.

Horritt, M. S. and Bates, P. D.: Evaluation of 1-D and 2-D numerical models for predicting river flood inundation, J. Hydrol., 268(14), 87-99, doi:10.1016/S0022-1694(02)00121-X, 2002.

Horritt, M. S.: Parameterisation, validation and uncertainty analysis of CFD models of fluvial and flood hydraulics in the natural environment, in: Computational Fluid Dynamics Applications in Environmental Hydraulics, edited by: Bates, P. D., Lane, S. N., and Ferguson, R. I., John Wiley and Sons Ltd, 193213, 2005.

Horritt, M. S., Bates, P. D., and Mattinson, M. J.: Effects of mesh resolution and topographic representation in 2-D finite volume models of shallow water fluvial flow, J. Hydrol., 329, 306314, 2006.

Hunter, N. M., Bates, P. D., Horritt, M. S., and Wilson, M. D.: Simple spatially-distributed models for predicting flood inundation: a review, Geomorphology, 90(3-4), 208-225, 2007.

Katul, G. G., Wiberg, P., Albertson, J., and Hornberger, G.: A mixing layer theory for flow resistance in shallow streams, Water Resour. Res., 38(11), 1250-1250, 2002.

Kouwen, N. and Li, R. M.: Biomechanics of vegetative channel linings, J. Hydr. Eng. Div.-ASCE, 106(6), 713-728, 1980.

Kouwen, N. and Fathi-Moghadam, M.: Friction factors for coniferous trees along rivers, J. Hydraul. Eng.-ASCE, 126(1), 732-740, 2000.

Lane, S. N., Hardy, R. J., Elliott, L., and Ingham, D. B.: Numerical modeling of flow processes over gravelly surfaces using structured grids and a numerical porosity treatment, Water Resour. Res., 40, W01302, doi:10.1029/2002WR001934, 2004.

Lane, S. N.: Roughness -time for a re-evaluation?, Earth Surf. Proc. Land., 30, 251-253, 2005.

Lane, S. N., Hardy, R. J., Ferguson, R. I., and Parsons, D. R.: A framework for model verification and validation of CFD schemes in natural open channel flows, in: Computational Fluid Dynamics Applications in Environmental Hydraulics, edited by: Bates, P. D., Lane, S. N., and Ferguson, R. I., John Wiley \& Sons Ltd, 169-192, 2005.

Lane, S. N. and Ferguson, R. I.: Modelling reach-scale fluvial flows, in: Computational Fluid Dynamics Applications in Environmental Hydraulics, edited by: Bates, P. D., Lane, S. N., and Ferguson, R. I., John Wiley \& Sons Ltd, 217-269, 2005.

Lane, S. N., Tayefi, V., Reid, S. C., Yu, D., and Hardy, R. J.: Interactions between sediment delivery, channel change, climate change and flood risk in a temperate upland environment, Earth Surf. Proc. Land., 32(3), 429-446, 2007.

Lane, S. N. and Carboneau, P. E.: High resolution remote sensing for understanding instream habitat, in: Hydroecology and Ecohydrology, edited by: Wood, P. E., Hannah, D. M. and Sadler, J. P. Wiley \& Sons, Ldt, 185-204, 2007.

Lane, S. N., Reid, S. C., Tayefi, V., Yu, D., and Hardy, R. J.: Reconceptualising coarse sediment delivery problems in rivers as catchment-scale and diffuse, Geomorphology, 98, 227-249, 2008.

Leclerc, M.: Ecohydraulics, A new interdisciplinary frontier for CFD, in: Computational Fluid Dynamics Applications in Environmental Hydraulics, edited by: Bates, P. D., Lane, S. N., and Ferguson, R. I., John Wiley \& Sons Ltd, 429-460, 2005.

Liu, X.: Airborne LiDAR for DEM generation: some critical issues, Prog. Phys. Geog., 32(1), 31-49, 2008.

Mandlburger, G. and Briese, C.: Using Airborne Laser Scanning for Improved Hydraulic Models, in: International Congress on Modelling and Simulation, 731-738, 2007.

Mandlburger, G., Hauer, C., Höfle, B., Habersack, H., and Pfeifer, N.: Optimisation of LiDAR derived terrain models for river flow modelling, Hydrol. Earth Syst. Sci., 13, 1453-1466, doi:10.5194/hess-13-1453-2009, 2009.

Marks, K. J. and Bates, P. D.: Integration of high resolution topographic data with floodplain flow models, Hydrol. Process., 14, 2109-2122, 2000.

Mason, D. C., Cobby, D. M., Horritt, M. S., and Bates, P. D.: Floodplain friction parameterization in two-dimensional river flood models using vegetation heights derived from airborne scanning laser altimetry, Hydrol. Process., 17, 1711-1732, 2003.

Nicholas, A. P.: Computational fluid dynamics modelling of boundary roughness in gravel-bed rivers: An investigation of the effects of random variability in bed elevation, Earth Surf. Proc. Land., 26, 345-362, 2001.

Nicholas, A. P.: Roughness parameterization in CFD modelling of gravel-bed rivers, in: Computational Fluid Dynamics Applications in Environmental Hydraulics, edited by: Bates, P. D., Lane, S. N., and Ferguson, R. I., John Wiley \& Sons Ltd, 329-355, 2005.

Omer, C. R., Nelson, E. J., and Zundel, A. K.: Impact of varied data resolution on hydraulic modelling and floodplain delineation, J. Am. Water. Resour. As., 39(2), 467-475, 2003. 
Poggi, D. and Katul, G. G.: The effect of canopy roughness density on the constitutive components of the dispersive stresses, Exp. Fluids, 45, 111-121, doi:10.1007/s00348-008-0467-7, 2008.

Poggi, D., Krug, C., and Katul, G. G.: Hydraulic resistance of submerged rigid vegetation derived from first-order closure models, Water Resour. Res., 45, W10442, doi:10.1029/2008WR007373, 2009.

Popescu, S. C. and Zhao, K.: A voxel-based LiDAR method for estimating crown base height for deciduous and pine trees, Remote Sens. Environ., 112, 767-781, 2008.

Raber, G.: The effect of LiDAR posting density on DEM accuracy and flood extent delineation, A GIS-simulation approach, Technical report, 2003

Schubert, J. E., Sanders, B. F., Smith, M. J., and Wright, N. G.: Unstructured mesh generation and landcover-based resistance for hydrodynamic modeling of urban flooding, Adv. Water Resour., 31, 1603-1621, 2008.

Sithole, G. and Vosselman G.: Experimental comparison of filter algorithms for bare earth extraction from airborne laser scanning point clouds, ISPRS J. Photogramm., 59(1-2), 85-101, 2004.

Straatsma, M. W. and Middelkoop, H.: Airborne laser scanning as a tool for lowland floodplain vegetation monitoring, Hydrobiologia, 565, 87-103, 2006.
Straatsma, M. W. and Baptist, M. J.: Floodplain roughness parameterization using airborne laser scanning and spectral remote sensing, Remote Sens. Environ., 112, 1062-1080, 2008.

Suarez, J. C., Ontiveros, C., Smith, S., and Snape, S.: Use of airborne LiDAR and aerial photography in the estimation of individual tree heights in forestry, Computers \& Geosciences, (31)2, 253-262, doi:10.1016/j.cageo.2004.09.015, 2005.

Tayefi, V., Lane, S. N., Hardy, R. J., and Yu, D.: A comparison of 1-D and 2-D approaches to modelling flood inundation over complex upland floodplains, Hydrol. Process., 21, 3190-3202, 2007.

Terrascan user's guide: http://www.terrasolid.fi/, 2001.

Wehr, A. and Lohr, U.: Airborne laser scanning - an introduction and overview, ISPRS J. Photogramm., 54, 68-82, 1999.

Yu, D.: Two-dimensional diffusion wave modelling of structurally complex floodplains, Ph.D. thesis, University of Leeds, UK, 2005.

Yu, D. and Lane, S. N.: Urban fluvial flood modelling using a twodimensional diffusion-wave treatment - Part 1: Mesh resolution effects, Hydrol. Process., 20(7), 1541-1565, 2006a.

Yu, D. and Lane, S. N.: Urban fluvial flood modelling using a twodimensional diffusion-wave treatment - Part 2: Development of a sub-grid-scale treatment, Hydrol. Process., 20(7), 1567-1583, 2006b. 